\title{
Risk indicators for tooth loss in adult workers
}

\section{Marília Jesus Batista ${ }^{(a)}$ \\ Lílian Berta Rihs(b) \\ Maria da Luz Rosário de Sousa(a)}

(a) Department of Community Dentistry,

Piracicaba Dental School, Univ of Campinas

- Unicamp, Piracicaba, SP, Brazil.

(b) Departament of Oral Health, Secretaria Municipal de Saúde de Piracicaba, Piracicaba, SP, Brazil.
Declaration of Interests: The authors certify that they have no commercial or associative interest that represents a conflict of interest in connection with the manuscript.

\section{Corresponding Author:}

Maria da Luz Rosário de Sousa

E-mail: luzsousa@fop.unicamp.br

Submitted: Mar 29, 2012

Accepted for publication: Jun 06, 2012

Last revision: Jul 27, 2012
Abstract: Tooth loss continues to be a prevalent condition in Brazilian adults and elderly individuals. The aim of this cross-sectional study, conducted among workers in a wholesale grocery chain in the State of São Paulo, was to identify risk indicators for tooth loss in adults. The presence of caries and periodontal status were examined in 387 adults aged 20-64 years, according to World Health Organization criteria. Two outcomes were analyzed: loss of one or more teeth, and loss of four or more teeth. Independent variables analyzed were demographic and socioeconomic factors, clinical conditions, use of dental services, and selfperceived oral health. Poisson regression models were used for multivariate statistical analysis. Participants were missing a mean of 5.38 teeth, and $76.9 \%(n=297)$ had lost at least one tooth; the most frequently lost teeth were permanent molars. Older age and the presence of visible dental biofilm were associated significantly with the two tooth loss outcomes $(\mathrm{p}<0.05)$. Individuals who had visited the dentist 3 or more years previously showed a lower prevalence of tooth loss (prevalence ratio $=0.79$; 95\% confidence interval, 0.68-0.91). Those with lower household incomes were significantly more likely to have lost four or more teeth (prevalence ratio $=1.35 ; 95 \%$ confidence interval, 1.07-1.70). Study results indicated that age and dental biofilm were risk indicators for tooth loss, independently of socioeconomic factors. These risk indicators should be considered when planning oral health programs for adults.

Descriptors: Oral Health; Adult; Epidemiology.

\section{Introduction}

Tooth loss in adults and elderly individuals continues to be an oral health hazard that has negative impacts on quality of life and interferes with work activities. ${ }^{1}$ Missing teeth can interfere with chewing ability, diction, and esthetics. Low self-esteem related to tooth loss can hinder an individual's ability to socialize, hamper the performance of work and daily activities, and lead to absence from work. ${ }^{2}$ Thus, the identification of tooth loss risk indicators in workers is an important public health measure.

Caries and periodontal disease are the main reasons for tooth loss in adults. ${ }^{3}$ In addition to clinical causes, other factors have been associated with tooth loss, such as the dental service used, time since the last visit to the dentist, reason for seeking treatment, and lifestyle, demographic and socioeconomic factors. ${ }^{4,5}$

Adults and elderly individuals in Brazil have a high number of missing 
teeth. In the first national oral health survey, conducted in 1988, missing teeth accounted for $65.4 \%$ of decayed/missing/filled teeth (DMFT) in adults aged 35-44 years, and 93\% of DMFT in elderly individuals (aged 65-74 years). ${ }^{6}$ The possession of functional teeth and the maintenance of oral health are extremely important for adults in order to carry out daily activities and to enjoy interpersonal relationships $^{2}$ and healthy aging; compromised health, including oral health, can interfere with the ability to work. Therefore, the objective of this study was to identify tooth loss indicators in adult workers in a wholesale grocery chain.

\section{Methodology Ethical issues}

This study was approved by the Research Ethics Committee of the Piracicaba School of Dentistry, University of Campinas (No. 122/2005). All adults who participated in the study provided written free and informed consent.

\section{Study design and location}

This cross-sectional study was conducted among adults who worked in a wholesale grocery chain. The company is located in the metropolitan region of São Paulo (Brazil), which has 19,889,559 inhabitants. ${ }^{7}$ Data were collected between July 2008 and August 2009.

\section{Sample}

Adults aged 20-64 years were recruited for this study. The sample size was calculated based on caries experience data from the most recent oral health study conducted in the State of São Paulo. Calculations were performed for two age ranges within the study group:

- for adults aged 20-29 years, the mean DMFT index of $8.86 \pm 5.1^{8}$ for the 19-year-old age group was used;

- for those aged 30-64 years, the mean DMFT index of $20.32 \pm 7.61^{9}$ for $35-44$-year-old adults was used.

A $95 \%$ confidence interval, 20\% accuracy, and design effect of 2 were adopted. To this total, $20 \%$ was added to compensate for possible losses and refusals, resulting in a calculated sample size of 376 volunteers. The sample was stratified by age after sample size calculation, and the age range for adults recommended by the World Health Organization (WHO) was used. Thus, the study sample was divided into three groups aged $20-34,35-44$, and 45-64 years.

Company managers were contacted in advance to explain the research procedure. Twenty-five visits were planned, and in each visit 16 employees were randomly selected, resulting in the selection of 400 adults. Two thousand employees comprised the study universe in 2009. All company employees were informed about the research, and the following inclusion criteria were applied:

- subjects had to be within the stipulated age range,

- have the cognitive ability to answer the questionnaire,

- agree to participate in the research.

The study was conducted until the number of participants equivalent to the sample size calculation was attained.

\section{Data collection}

Oral examinations were conducted in the internal environment of the company under natural lighting using oral mirrors and community periodontal index (CPI) probes, as recommended by the WHO. The examiner was trained by a reference examiner via a total of 8 hours of theoretical and practical discussions, until at least $90 \%$ concordance in the assessment of coronal caries was obtained. ${ }^{10}$ Intraexaminer agreement was $98.5 \%$, within the standard of reliability. ${ }^{11}$

Coronal tooth decay and periodontal status were clinically assessed. ${ }^{12}$ Caries was assessed using the DMFT index, periodontal status was verified by the CPI index, and dental biofilm was assessed using the criteria of Ainamo and Bay. ${ }^{13}$

Each participant completed a 61-item questionnaire that was prepared for the purpose of collecting demographic and socioeconomic data, and assessing factors related to general and oral health. Some ques- 
tions were taken from a national survey conducted in $2003,{ }^{14}$ and others were developed for the study and were validated by pilot studies in adults prior to the beginning of research. The questionnaire was self-administered and participants were assured of confidentiality to prevent possible information bias due to their status as company employees.

\section{Statistical analysis}

Data were tabulated in SPSS 17.0 software (IBM, Chicago, USA) and Microsoft Excel. First, a descriptive analysis of studied variables was performed. In separate analyses, the following two tooth loss outcomes were used as dependent variables:

- (1) participants who had lost no teeth were compared with those who had lost one or more teeth, and

- (2) participants who had lost up to three teeth (that was the median number of teeth lost) were compared with those who had lost four or more teeth.

The independent variables studied were dichotomized and reclassified to verify associations with outcomes. The age variable was divided into three groups: $20-34,35-44$, and $45-64$ years. The cutoff point for personal and household income monthly was the median, US\$588.24. Education was classified into three groups: $\leq 8$ years (elementary school), 9-11 years (high school), and > 11 years (complete or incomplete higher education). Employees' occupations were classified as skilled, partly skilled, or unskilled. The type of service used for the last visit to the dentist was categorized as a public, private, or health insurance clinic, and the time of the last visit was recorded as $<1,1-2$, or $\geq 3$ years previously. Reasons for going to the dentist were grouped into routine examination, pain, or other; and participants' assessment of the service received was dichotomized as good or not good. The clinical variables used in the analysis were clinical attachment loss $(\mathrm{CAL}) \geq 4 \mathrm{~mm}$, presence of untreated carious lesions, need for treatment, and presence of dental biofilm.

Bivariate analyses were conducted, and all independent variables yielding $\mathrm{p}$-values $<0.25$ were included in the Poisson regression analyses with ro- bust variance.

\section{Results}

A total of 386 adults [54.7\% $(\mathrm{n}=211)$ female] aged 20-64 (mean, 32.65) years who worked in the metropolitan region of São Paulo were examined. Of 400 employees selected, 14 refused to participate.

In the total sample, caries experience, measured by the DMFT index, was $14.56 \pm 8.31$ and the mean number of missing teeth was $5.47 \pm 6.81$. Only $1.9 \%(7 / 386)$ of workers examined were edentulous, and $76.9 \%(\mathrm{n}=297)$ had lost at least one tooth. The distribution of tooth loss in the sample is shown in Figure 1. The most frequently lost teeth were the permanent first molars (Figure 2).

Prevalence ratios (PRs) for the outcome of the loss of one or more teeth are shown in Table 1. After adjustment in the regression model, the highest prevalence of tooth loss was found in individuals aged 45-64 years, followed by those who had dental biofilm and those who had visited the dentist $<1$ year previously (Table 1). Univariate analysis revealed associations with the same variables, as well as with smoking habit $(\mathrm{PR}=1.28 ; \mathrm{p}<0.05$; Table 2). Older ager, lower income, and presence of visible dental biofilm influenced the prevalence of the loss of four or more teeth (Table 2).

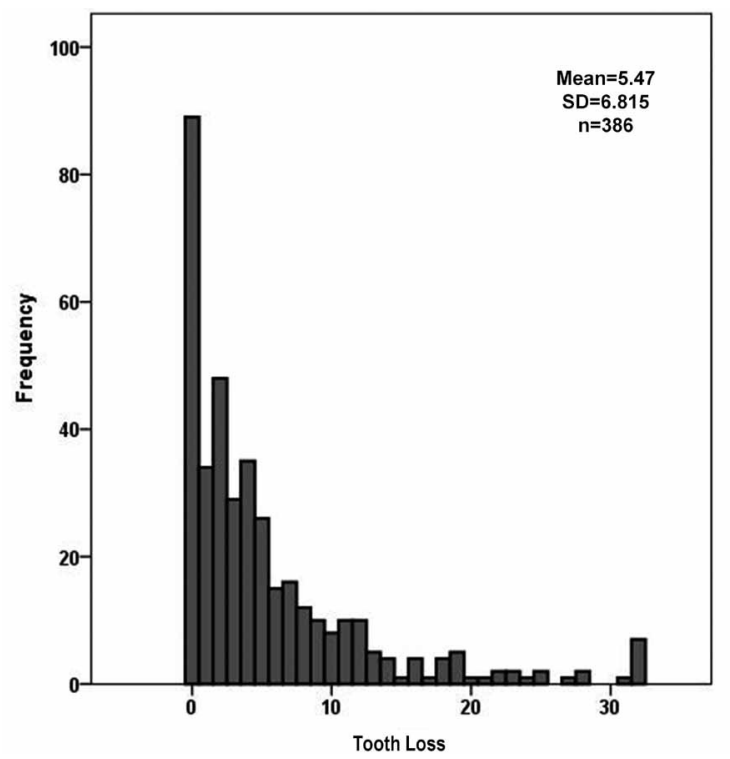

Figure 1 - Histogram of missing teeth in workers, São Paulo, SP, Brazil, 2009 


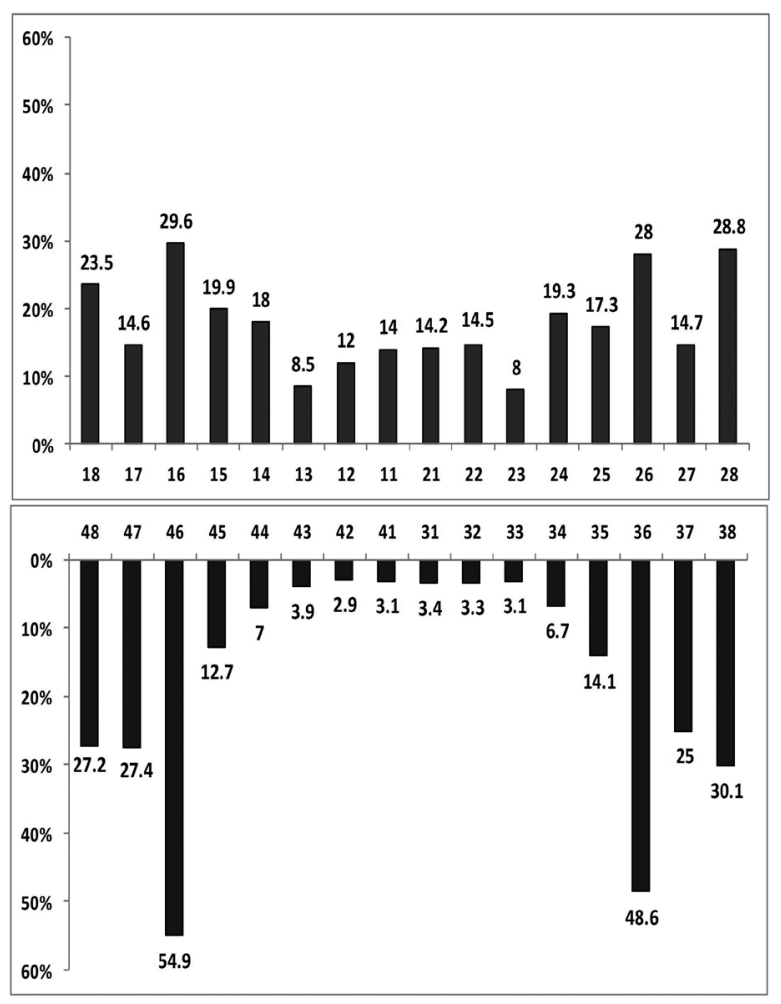

Figure 2 - Distribution of missing teeth by maxillary and mandibular elements, São Paulo, SP, Brazil, 2009.

\section{Discussion}

In this study, $76.9 \%$ of examined workers aged 20-64 years had lost one or more teeth. Older age and the presence of dental biofilm were associated with tooth loss in the two regression analyses. Risk indicator assessment according to the number of missing teeth has been poorly addressed in existing studies, and differences may exist. In this study, the loss of four or more teeth was associated with the socioeconomic factor. Reducing the number of missing teeth among adults and elderly individuals is a WHO global oral health goal for $2020,{ }^{14}$ and knowledge of the risk indicators is extremely important for the purpose of establishing oral health programs to prevent new tooth loss.

Previous national surveys have shown a large increase in the number of missing teeth ${ }^{9,15}$ among adolescents (aged 15-19 years), adults (aged 35-44 years), $, 15,16$ and elderly individuals (aged 65-74 years). Elderly individuals have further shown a high prevalence of edentulism and high DMFT indices. ${ }^{15}$ The identification of risk indicators for tooth loss in an extended age range is relevant to the development of tooth loss prevention measures.

In the present study, the distribution of tooth loss in Brazilian adults aged 35-44 years ${ }^{4}$ was asymmetric: those with the highest number of missing teeth formed a small proportion of the population. This distribution suggests that tooth loss has a polarizing effect, as occurs with tooth decay in children. ${ }^{17}$

In agreement with the findings of Corraini et al., ${ }^{18}$ the most frequently extracted teeth in our study sample were the permanent maxillary first molars, likely because they are among the first permanent teeth to erupt and are thus more susceptible to the development of caries, which has been identified as the main cause of tooth loss. ${ }^{18,19}$

This study was conducted in a homogeneous group with respect to gender and socioeconomic characteristics. Age and dental biofilm were related to tooth loss in the two analyses. Other studies have also identified age as a risk factor for tooth loss. ${ }^{4,5,18,20,21}$ The influence of age on tooth loss may have a cohort effect, which is explained by differences in national health policies implemented in the country's history. In Brazil and worldwide, the practice of tooth extraction accompanied the increasing incidence of caries in the $16^{\text {th }}$ and $17^{\text {th }}$ centuries. ${ }^{4,17}$ The Brazilian Federal Council of Odontology was established in 1964 to oversee dental service in Brazil, which was still practiced by professionals who were not qualified in dentistry ${ }^{22}$ and who routinely performed extractions. Thus, adults aged 45-64 years at the time of the present study were born between 1945 and 1964, when public oral health policies were almost non-existent.

Adults aged 35-44 years were born in 19651974, during which time the Brazilian National Institute of Medical Assistance and Welfare was created. The establishment of this institute reflects the beginning of the state's concern with health, but dental practice remained based on the model of restorative surgery. ${ }^{22}$ During the 1980 s, around the time that the youngest participants in the study group (20-34 years) were born (1975-1989), fluoridation was implemented in Brazilian cities; thus, most of these participants benefited from the presence of fluoride in drinking water. In addition, the National 
Table 1 - Results of Poisson regression analysis for the loss of one or more teeth among workers in São Paulo, Brazil, 2009.

\begin{tabular}{|c|c|c|c|c|c|c|c|c|c|}
\hline & & $\begin{array}{c}\text { No tooth loss } \\
n(\%)\end{array}$ & $\begin{array}{c}\text { Tooth loss } \\
\text { n (\%) }\end{array}$ & $\begin{array}{l}\text { Crude } \\
\text { PR }\end{array}$ & $95 \% \mathrm{Cl}$ & $p$ & $\begin{array}{l}\text { Adjusted } \\
\text { PR }\end{array}$ & $95 \% \mathrm{Cl}$ & $\mathrm{p}$ \\
\hline \multirow{3}{*}{ Age (years) } & $45-64$ & $1 \quad(2.0)$ & $50(98.0)$ & 1.53 & $1.39-1.70$ & $<0.01$ & $1.51^{*}$ & $1.35-1.68$ & $<0.01$ \\
\hline & $35-45$ & $1 \quad(1.1)$ & $93(98.9)$ & 1.55 & $1.41-1.71$ & $<0.01$ & $1.49^{*}$ & $1.35-1.64$ & $<0.01$ \\
\hline & $20-34$ & $87(36.1)$ & $154(63.9)$ & 1 & & & 1 & & \\
\hline \multirow{2}{*}{$\begin{array}{l}\text { Household income } \\
\text { (Brazilian reais) }\end{array}$} & $>1000.00$ & $12(13.5)$ & 77 (86.5) & 1.18 & $1.05-1.33$ & $<0.01$ & - & & \\
\hline & $<1000.00$ & $46(26.7)$ & $126(73.3)$ & 1 & & & & & \\
\hline \multirow{3}{*}{$\begin{array}{l}\text { Education } \\
\text { (years) }\end{array}$} & $<8$ & $4 \quad(5.5)$ & $69(94.5)$ & 1.37 & $1.10-1.70$ & $<0.01$ & - & & \\
\hline & $9-11$ & $73(26.6)$ & 201 (73.4) & 1.06 & $0.85-1.32$ & 0.61 & - & & \\
\hline & $>11$ & $12(30.8)$ & $27(69.2)$ & 1 & & & & & \\
\hline \multirow{3}{*}{ Occupation } & Unskilled & $18(14.8)$ & $104(85.2)$ & 1.21 & $1.05-1.39$ & $<0.01$ & - & & \\
\hline & Intermediate & $38(25.0)$ & $114(75.0)$ & 1.06 & $0.91-1.24$ & 0.42 & - & & \\
\hline & Skilled & $33(29.5)$ & $79(70.5)$ & 1 & & & & & \\
\hline \multirow{2}{*}{ Marital status } & With partner & $30(16.9)$ & $148(83.1)$ & 1.17 & $1.05-1.30$ & $<0.01$ & - & & \\
\hline & Without partner & $59(28.6)$ & 147 (71.4) & 1 & & & & & \\
\hline \multirow{3}{*}{$\begin{array}{l}\text { Time since last visit } \\
\text { to dentist (years) }\end{array}$} & $\geq 3$ & $24(28.9)$ & $59(71.1)$ & 0.88 & $0.76-1.03$ & 0.12 & $0.79^{*}$ & $0.68-0.91$ & $<0.01$ \\
\hline & $1-2$ & $21(21.4)$ & 77 (78.6) & 0.98 & $0.86-1.10$ & 0.72 & 0.96 & $0.85-1.08$ & 0.48 \\
\hline & $<1$ & $38(19.6)$ & $156(80.4)$ & 1 & & & 1 & & \\
\hline \multirow{2}{*}{$\begin{array}{l}\text { Self-perceived } \\
\text { health }\end{array}$} & Not good & $14(15.6)$ & $76(84.4)$ & 1.13 & $1.01-1.27$ & 0.03 & & & \\
\hline & Good & $70(25.4)$ & $206(74.6)$ & 1 & & & & & \\
\hline \multirow{2}{*}{$\begin{array}{l}\text { Self-perceived } \\
\text { oral health }\end{array}$} & Not good & $36(17.2)$ & $173(82.8)$ & 1.17 & $0.90-1.13$ & $<0.01$ & 1.10 & $0.98-1.23$ & 0.09 \\
\hline & Good & $46(29.7)$ & 109 (70.3) & 1 & & & 1 & & \\
\hline \multirow{2}{*}{ Dental biofilm } & Yes & $21(15.2)$ & $117(84.8)$ & 1.16 & $1.53-1.30$ & $<0.01$ & $1.11^{*}$ & $1.01-1.23$ & 0.04 \\
\hline & No & $67(27.5)$ & 177 (72.5) & 1 & & & 1 & & \\
\hline \multirow{2}{*}{$\mathrm{CAL} \geq 4 \mathrm{~mm}$} & Yes & $27(15.1)$ & $152(84.9)$ & 1.21 & $1.10-1.35$ & 0.01 & - & & \\
\hline & No & $62(30)$ & $145(70)$ & 1 & & & & & \\
\hline \multirow{2}{*}{ Caries } & Yes & $38(19.7)$ & $155(80.3)$ & 1.09 & $0.98-1.22$ & 0.12 & - & & \\
\hline & No & $51(26.4)$ & $142(73.6)$ & 1 & & & - & & \\
\hline
\end{tabular}

Note: CAL, clinical attachment loss; PR, prevalence ratio; $\mathrm{Cl}$, confidence interval. ${ }^{*} p<0.05$ in Poisson regression model.

Health Service was consolidated in $1988^{17,22}$ and oral health was recognized as an integral part of general health to which everyone had the right. ${ }^{22}$ These historical developments may explain the higher number of missing teeth observed in our oldest participants.

Many studies have associated tooth loss with age, but few have examined its association with the presence of dental biofilm. Hamashi et al. ${ }^{23}$ found more tooth loss in subjects who brushed their teeth less frequently. Dental biofilm is directly related to the development of caries and periodontal disease, which are the factors most frequently responsible for tooth loss. ${ }^{19}$
In our analyses, socioeconomic factors showed an association only with the loss of four or more teeth. As in this study, other studies have also observed an association between lower income and tooth loss. ${ }^{4,5,20}$ The main reason for participant's choice of tooth extraction rather than treatment seemed to be financial. ${ }^{23}$ The reasons for tooth loss are complex, involving not only physiological causes and socioeconomic associations, but also other factors such as personal attitudes and beliefs. ${ }^{23}$

One limitation of this study is the use of a convenience sample of workers from a single company. However, few studies have examined the oral health 
Table 2 - Results of Poisson regression analysis for the loss of 4 or more teeth among workers in São Paulo, Brazil, 2009.

\begin{tabular}{|c|c|c|c|c|c|c|c|c|c|}
\hline & & $\begin{array}{c}0-3 \text { teeth lost } \\
n(\%)\end{array}$ & $\begin{array}{c}\geq 4 \text { teeth lost } \\
\mathrm{n}(\%)\end{array}$ & $\begin{array}{l}\text { Crude } \\
\text { PR }\end{array}$ & $95 \% \mathrm{Cl}$ & $p$ & $\begin{array}{c}\text { Adjusted } \\
\text { PR }\end{array}$ & $95 \% \mathrm{Cl}$ & $\mathrm{p}$ \\
\hline \multirow{3}{*}{ Age (years) } & $45-64$ & 7 (13.7) & 44 (86.3) & 3.35 & $2.64-4.27$ & $<0.01$ & $3.64^{*}$ & $2.64-5.01$ & $<0.01$ \\
\hline & $35-45$ & $14(14.9)$ & $80(85.1)$ & 3.31 & $2.63-4.17$ & $<0.01$ & $3.63^{*}$ & $2.71-4.86$ & $<0.01$ \\
\hline & $20-34$ & $179(74.3)$ & $62(25.7)$ & 1 & & & 1 & & \\
\hline \multirow{2}{*}{$\begin{array}{l}\text { Household income } \\
\text { (Brazilian reais) }\end{array}$} & $>1000.00$ & $102(62.2)$ & $65(37.8)$ & 1.58 & $1.22-2.04$ & $<0.01$ & $1.35^{*}$ & $1.07-1.70$ & 0.01 \\
\hline & $<1000.00$ & $36(40.4)$ & $53(59.6)$ & 1 & & & 1 & & \\
\hline \multirow{3}{*}{ Education (years) } & $<8$ & 16 (21.9) & $57(78.1)$ & 2.54 & $1.53-4.13$ & $<0.01$ & - & & \\
\hline & $9-11$ & $157(53.7)$ & $117(42.7)$ & 1.39 & $0.85-2.27$ & 0.19 & - & & \\
\hline & $>11$ & $27(69.2)$ & $12(30.8)$ & 1 & & & & & \\
\hline \multirow{3}{*}{ Occupation } & Unskilled & $51(41.8)$ & $71(58.2)$ & 1.59 & $1.19-2.12$ & $<0.01$ & - & & \\
\hline & Intermediate & 78 (51.3) & $74(48.7)$ & 1.33 & $0.99-1.78$ & 0.06 & - & & \\
\hline & Skilled & $71(63.4)$ & $41(36.6)$ & 1 & & & & & \\
\hline \multirow{2}{*}{ Marital status } & With partner & $73(41.0)$ & $105(59)$ & 1.52 & $1.23-1.88$ & $<0.01$ & - & & \\
\hline & Without a partner & $126(61.2)$ & $80(38.8)$ & 1 & & & & & \\
\hline \multirow{3}{*}{$\begin{array}{l}\text { Time since last visit } \\
\text { to dentist (years) }\end{array}$} & $\geq 3$ & $37(44.6)$ & $46(55.4)$ & 0.86 & $0.67-1.09$ & 0.21 & - & & \\
\hline & $1-2$ & $51(52.0)$ & $47(48.0)$ & 0.87 & $0.65-1.15$ & 0.32 & - & & \\
\hline & $<1$ & $102(52.6)$ & $92(47.4)$ & 1 & & & & & \\
\hline \multirow{3}{*}{$\begin{array}{l}\text { Reason for visit } \\
\text { to dentist }\end{array}$} & Other & $43(55.8)$ & $34(44.2)$ & 0.92 & $0.69-1.22$ & 0.56 & - & & \\
\hline & Pain & $43(44.8)$ & $53(55.2)$ & 1.14 & $0.91-1.44$ & 0.25 & - & & \\
\hline & Routine check-up & $105(51.7)$ & $98(48.3)$ & 1 & & & & & \\
\hline \multirow{2}{*}{$\begin{array}{l}\text { Self-perceived } \\
\text { health }\end{array}$} & Not good & $36(40.0)$ & $54(60.0)$ & 1.37 & $1.10-1.70$ & $<0.01$ & - & & \\
\hline & Good & 155 (52.2) & $121(43.8)$ & 1 & & & & & \\
\hline \multirow{2}{*}{$\begin{array}{l}\text { Self-perceived } \\
\text { oral health }\end{array}$} & Not good & $96(45.9)$ & $113(54.1)$ & 1.37 & $1.10-1.73$ & $<0.01$ & - & & \\
\hline & Good & $94(60.6)$ & $61(39.4)$ & 1 & & & & & \\
\hline \multirow{2}{*}{ Smoking } & Yes & $29(41.4)$ & $41(58.6)$ & 1.28 & $1.01-1.61$ & 0.04 & - & & \\
\hline & No & $171(54.1)$ & $145(45.9)$ & 1 & & & & & \\
\hline \multirow{2}{*}{ Dental biofilm } & Yes & $57(41.3)$ & $81(58.7)$ & 1.40 & $1.15-1.72$ & $<0.01$ & $1.35^{*}$ & $1.07-1.70$ & 0.01 \\
\hline & No & $142(58.2)$ & $102(41.8)$ & 1 & & & 1 & & \\
\hline \multirow{2}{*}{$\mathrm{CAL} \geq 4 \mathrm{~mm}$} & Yes & 75 (41.9) & $104(58.1)$ & 1.48 & $1.19-1.81$ & $<0.01$ & $0.84^{*}$ & $0.66-1.07$ & 0.17 \\
\hline & No & $125(60.4)$ & 82 (39.6) & 1 & & & 1 & & \\
\hline \multirow{2}{*}{ Bleeding } & Yes & $164(53.9)$ & $140(46.1)$ & 0.82 & $0.65-1.03$ & 0.08 & $1.19^{*}$ & $0.95-1.50$ & 0.12 \\
\hline & No & $36(46.9)$ & $46(56.1)$ & 1 & & & 1 & & \\
\hline
\end{tabular}

Note: CAL, clinical attachment loss; PR, prevalence ratio; $\mathrm{Cl}$, confidence interval. ${ }^{*} \mathrm{p}<0.05$ in Poisson regression model.

of workers because of the difficulty of conducting research within companies, which may yield data that differ from those of studies using household samples. The cross-sectional design of the study prevented us from drawing causal inferences in relation to tooth loss. Despite these limitations, this original study of workers with a wide age range features a study sample that requires investigation. Thus, fur- ther studies of tooth loss in working adults should be conducted.

Because the cumulative effects of tooth loss can be observed in adults and elderly individuals, health promotion programs for young adults should be implemented to prevent further tooth loss and promote healthy aging. The identification of factors associated with tooth loss is necessary to guide the 
development of strategies that provide access to $\mathrm{cu}-$ rative treatment and improve the prevention of oral diseases.

\section{Conclusions}

This study of adult workers found that older age and the presence of dental biofilm were risk indicators for tooth loss, independently of socioeconomic

\section{References}

1. Gerritsen AE, Allen PF, Witter DJ, Bronkhorst EM, Creugers NHJ. Tooth loss and oral health-related quality of life: a systematic review and meta-analysis. Health Qual Life Outcomes. 2010 Nov 5;8:126.

2. Petersen PE. The World Oral Health Report 2003: continuous improvement of oral health in the 21st century - the approach of the WHO Global Oral Health Programme. Community Dent Oral Epidemiol. 2003 Dec;31(Suppl. 01):3-24.

3. Steele JG, Treasure E, Pitts NB, Morris J, Brandnock G. Total tooth loss in the United Kingdom in 1998 and implications for the future. Br Dent J. 2000 Dec;189(11):598-603.

4. Barbato PR, Nagano HCM, Zanchet FN, Boing AF, Peres MA. [Tooth loss and associated socioeconomic, demographic, and dental-care factors in Brazilian adults: an analysis of the Brazilian Oral Health Survey, 2002-2003]. Cad Saude Publica. 2007 Aug;23(8):1803-14. Portuguese.

5. Silva DD, Rihs LB, Sousa MRL. [Factors associated of maintenance of teeth in adults in the state of São Paulo, Brazil]. Cad Saude Publica. 2009 Nov;25(11):2407-18. Portuguese.

6. Brasil. Ministério da Saúde. [Epidemiological survey of oral health: Brazil, Urban Zone.] Brasília (DF): Centro de Documentação do Ministério da Saúde; 1988. 137 p. [cited 2009 Oct 15]. Available from: http://dab.saude.gov.br/cnsb/sbbrasil/ arquivos/apresentacao_abbrasil_2010.pdf. Portuguese.

7. Instituto Brasileiro de Geografia e Estatística (IBGE) [homepage]. Brasília (DF): Instituto Brasileiro de Geografia e Estatística. [cited 2009 Jan 11]. Available from: www.ibge.gov.br.

8. Gushi LL, Soares MC, Forni TIB, Vieira V, Wada RS, Sousa MLR. [Dental caries in 15-19 year-old adolescents in São Paulo State, Brazil, 2002]. Cad Saude Publica. 2005 SepOct;21(5):1383-91. Portuguese.

9. São Paulo. Secretaria de Estado da Saúde. Universidade de São Paulo. [Oral health conditions in the State of São Paulo in 2002.] São Paulo (SP): Secretaria de Estado da Saúde. [cited 2009 Oct 15]. Available from: http://www.saude.sp.gov.br/ resources/ses/perfil/profissional-da-saude/grupo-tecnico-deacoes-estrategicas-gtae/saude-bucal/artigos-e-teses/estudosepidemiologicos/estudosepidemiologicos/condicoes_de_ saude_bucal_-_2002.pdf. Portuguese

10. World Health Organization. Basic methods. Geneva: World Health Organization; 1987. factors. These risk indicators should be considered when planning oral health programs for adults.

\section{Acknowledgements}

The authors thank the São Paulo Research Foundation for supporting this research (Nos. 2007/57547-0 and 2008/53309-0).

11. Frias AC, Antunes JLF, Narvai PC. [Reliability and validity of oral health surveys: dental caries in the city of Sao Paulo, 2002]. Rev Bras Epidemiol. 2004 Jun;7(2):144-54. Portuguese.

12. World Health Organization. Oral heath surveys: basic methods. 4th ed. Geneva: World Heath Organization; 1997.

13. Ainamo J, Bay I. Problems and proposals for recording gingivitis and plaque. Int Dent J. 1975 Dec;25(4):229-35.

14. Hodbell M, Petersen PE, Clarkson J, Johnson N. Global goals for oral health 2020. Int Dent J. 2003 Oct;53(5):285-8.

15. Brasil. Ministério da Saúde. [SB Brasil 2003: oral health conditions in the Brazilian population 2002/2003: main results.] Brasília: Ministry of Health; 2004.68 p. [cited 2009 Oct 15]. Available from: http://dab.saude.gov.br/cnsb/vigilancia.php. Portuguese.

16. Brasil. Ministério da Saúde. [Laughing Brazil: taking oral health seriously, 2010.] [cited 2011 January 28]. Available from: http://dab.saude.gov.br/cnsb/sbbrasil/arquivos/apresentacao_abbrasil_2010.pdf. Portuguese.

17. Narvai PC, Frazão P, Roncalli AG, Antunes JL. [Dental caries in Brazil: decline, polarization, inequality and social exclusion]. Rev Panam Salud Publica. 2006 Jun;9(6):385-93. Portuguese.

18. Corraini P, Baelum V, Pannuti CM, Pustiglioni AN, Romito GA, Pustiglioni FE. Tooth loss prevalence and risk indicators in an isolated population of Brazil. Acta Odontol Scand. 2009 Jun;67(5):297-303.

19. Fure S. Ten-year incidence of tooth loss and dental caries in elderly Swedish individuals. Caries Res. 2003 NovDec;37(6):462-9.

20. Moreira RS, Nico LS, Barrozo LV, Pereira JCR. Tooth loss in Brazilian middle-aged adults: multilevel effects. Acta Odontol Scand. 2010 Sep;68(5):269-77.

21. Steele JG, Sanders AE, Slade GD, Allen PF, Lahti S, Nuttall AJ, et al. How do age and tooth loss affect oral health impacts and quality of life? A study comparing two national samples. Community Dent Oral Epidemiol. 2004 Apr;32(2):107-14.

22. Antunes JLF, Narvai PC. Dental health policies in Brazil and their impact on health inequalities. Rev Saúde Pública. 2010 Apr;44(2):360-5.

23. Hamasha AH, Sasa I, Al Qudah M. Risk indicators associated with tooth loss in Jordanian adults. Community Dent Oral Epidemiol. 2000 Feb;28(1):67-72. 